\title{
The Establishment and Analysis of the Variable System for Assessing the Social Impact of Large-Scale Projects in China
}

\author{
L. Shen ${ }^{1,2,}{ }^{*}$, Z.H. Wang ${ }^{2}$ and Y.L. Huang ${ }^{3}$ \\ ${ }^{1}$ Faculty of Civil Engineering, Nanjing Tech University, Nanjing 210000, China; ${ }^{2}$ Business School of Hohai University, \\ Nanjing, 210098, P.R. China; ${ }^{3}$ Faculty of Civil Engineering, Southeast University, Nanjing 210000, China
}

\begin{abstract}
The social impact assessment of large-scale projects could help effectively control, prevent, or mitigate possible negative impacts caused by such projects, and thus has been gradually developed nationally and internationally. However, due to some inherent problems, conventional index assessment system could not accurately measure and evaluate the social impact over local communities. As a new method of social impact assessment, the variable analysis system has been proposed recently. The present study first provides a list of variable analysis systems for assessing the social impact of large-scale projects in China. It is worth noting that these systems are based on China's specific situations, and we further provide an in-depth analysis of available variables that have been commonly implemented by foreign countries for social impact assessment, including 32 assessment variables developed and used by Interorganizational Committee. Furthermore, with the application of DEMATEL-based method, the present study analyzes the interdependent relationships among all variables in our selected variable system, and establishes the procedures for determining the causal and effect variables. Finally, with GangKouwan Reservior Project as the example, the validity of using variable analysis system for assessing the social impact of a reservoir project is tested with DEMATEL method specifically implemented. Overall, the present study could help provide solid evidence and reference for assessing the social impact of large-scale projects, and for addressing parsimony issues by simplifying variables.
\end{abstract}

Keywords: DEMATEL, large-scale projects, social impact assessment, the variable analysis, the variable system.

\section{INTRODUCTION}

As China is experiencing rapid urbanization and industrialization development, more and more large-scale projects, such as hydraulic engineering projects, railway and highway construction projects, harbor engineering projects and petrochemical engineering projects have been gradually launched. However, such large-scale projects could also impose significant social impacts, and inevitably cause intensive social conflicts. As stated in The Blue Book issued by Chinese Academy of Social Sciences in 2013, more than ten thousand mass group incidents (large protests) have occurred each year, mainly due to a variety of social conflicts. For example, mass group incidents caused by conflicts of land acquisition, labor dispute, as well as other social conflicts account for $50 \%, 30 \%$ and $20 \%$ of total incidents, respectively [1]. Since the impacts of large-scale projects on the entire society have received wide public attention, the practice of social impact assessment has been gradually developed and established. However, the conventional social impact assessment is based the index assessment method, which requires many complicated social impact indexes. Also, it could not effectively evaluate some components of social impacts arising from complicated causal-effect mechanisms, especially for cases of higher-level impacts or cumulative impacts [2].

*Address correspondence to this author at the Business School of Hohai University, Nanjing, 210098, P.R. China and Faculty of Civil Engineering, Nanjing University of Technology, Nanjing 210000, China;

Tel: 0086025 58139853; Fax: 0086025 84733099; E-mail: s17455@sina.com
Relevant literature review shows that the practice of social impact assessment in developed countries has undergone noticeable changes from conventional index assessment method towards new variable analysis method, with the aim of analyzing the social impact of large-scale projects, identifying the contributing factors, and determining the social interactions and determinants of such interactions [3, 4]. This study is based on an in-depth analysis of experience and expertise that developed countries have accumulated during the practice of social impact assessment. Furthermore, it proposes the appropriate variable system that suits China's specific situations. Also, with the application of Decision Making Trial and Evaluation Laboratory (DEMATEL), the interdependent relationships among variables selected from a list of established variable analysis systems, as well as some key variables could be determined, in order to serve the purpose of providing necessary theoretical basis and practical reference for the practice of social impact assessment.

\section{THE ESTABLISHMENT OF THE VARIABLE ANALYSIS SYSTEM FOR ASSESSING THE SOCIAL IMPACT OF LARGE-SCALE PROJECTS IN CHINA}

\subsection{Literature Review of Studies On Social Impact Assessment In Foreign Countries}

The variables of a social impact assessment refer to the measurable changes in the population, community and social relationship. Such changes are generally caused by the alteration of related policies or development projects, and are 
formed on the basis of early environmental impact assessment, literature and materials related to social impact assessment, or environmental impact statement [5]. For the measurement of involving variables of social impact assessment, the major information source is project parameters, the census and other demographic data, local government information, community observation and public participation information. In 1994, the Guidelines and Principles for Social Impact Assessment issued by Interorganizational Committee listed 32 variables commonly used for social impact assessment, which could be categorized as five components, including population impacts, community systems, political and social resources, individual and household impacts, as well as community housing and infrastructure needs [6]. Based on such guidelines and principles, Rabel Burdge from the committee first proposed a list of social impact assessment variables with 28 items [7], and several scholars also proposed their own lists of social impact assessment variables. Generally speaking, the focus of these scholars is on the aspects of population impacts, community systems, community changes, political resources and community infrastructure need $[8,9]$.

\subsection{The List of Variables for Social Impact Assessment of Large-scale Projects in China}

In China, the evaluation index system has been widely used during the practice of social impact assessment. Since the process of assigning index weight is subjective, social impact assessment would be inevitably distorted to some extent. Therefore, it is meaningful to select appropriate variable analysis system for assessing social impacts that suits China's situations well, and such practice would be very helpful for the development of social impact assessment system in China.

Since China is still a developing country with unbalanced regional development, available projects tend to give more attention to issues related to poverty, development and peace (e.g., redistribution of benefits, rights and obligations of the different social groups), or, in other words, the focus is on the sustainable development of the entire society in general, and the community that suffers a sharp interest loss during the process of economic development in particular. By contrast, in most developed countries, their focus has been shifted towards the impacts of launched projects on resident adaptability, community culture, technological progress and social structure. In the present study, we categorize variable for assessing the social impact of large-scale projects in China as five components, including population impacts, resident living habits, community systems, political and social resources, as well as community infrastructure, based on China's specific situations and experience drawn from the lists of social impact assessment variables used by foreign countries, with the concept and definition of each index component shown in Table $\mathbf{1}$.

\section{DEMATEL-BASED VARIABLE ANALYSIS FOR ASSESSING SOCIAL IMPACTS IMPOSED BY LARGE-SCALE PROJECTS}

\subsection{The Principles and Applications of DEMATEL}

DEMATEL is a method first proposed by American scholars that combines the graph theory and matrix theory.
Through calculating the causality and centrality degree of each factor, this method could determine the causal-effect relationships among all factors, as well as the relative importance of each factor. Therefore, this method could simplify otherwise complex questions, and is generally considered as an effective method during the process of factor analysis and identification [10]. Since this method is ideal for testing the interdependent relationships among factors within a complex system, it has been widely applied in different fields such as geographical environment assessment, global problem analysis, business planning and decision-making, urban planning and design, as well as control systems and safety issues to reduce the number of indexes needed $[11,12]$. It's raised by Taylor in 2004, that social impact should be explored using analysis method instead of the method of encyclopedic. Focal point should be focused on the social impact while scoping. A mental structure regards to social field should be established first before key variables are picked up while choosing the variables relate to social change. [9]. Stolp and his colleagues believe that, an evaluation that lacks local defined variables may magnify the risk of its social impact not being recognized. Variables should be defined basing on the participatory interactive community counseling [13]. DEMATEL is able to take full advantage of experts' experience and knowledge to manage complicate social problems, especially effective in the systems whose factors have indeterminacy relationships [14]. As long as specialists of the related field are invited to help choosing key factors and the number as well as the composition of invited expert group is appropriate, the method mentioned above can determine the social impacting key factors of a certain project quickly and efficiently.

Therefore, the current study implements DEMATEL for assessing social impacts imposed by large-scale projects, with the hope that the key variables could be identified from a long list of social impact variables, and solid evidence could be provided for the decision making and management process.

\subsection{The Variable Analysis for Assessing Social Impacts Imposed by Large-scale Projects}

\subsubsection{A Direct Influence of the Interdependent Relation- ships Among Variables Over the Establishment of Matrix}

The study of the interdependent relationships among variables for assessing social impacts imposed by large-scale projects that are DEMATEL-based has a priority task, that is, to statistically analyze the interdependent relationships among variables via surveying and interviewing experts and stakeholders, and to establish a direct impact matrix $\mathrm{V}$ of studied variables [15]:

$$
\mathrm{V}=\left[\begin{array}{cccc}
0 & \mathrm{v}_{12} & \cdots & \mathrm{v}_{1 \mathrm{n}} \\
\mathrm{v}_{21} & 0 & \cdots & \mathrm{v}_{2 \mathrm{n}} \\
\vdots & \vdots & \cdots & \vdots \\
\mathrm{v}_{\mathrm{n} 1} & \mathrm{v}_{\mathrm{n} 2} & \cdots & 0
\end{array}\right]=\left(\mathrm{v}_{\mathrm{ij}}\right)_{\mathrm{n} \times \mathrm{n}}
$$

where, $\mathrm{v}_{\mathrm{ij}}$ represents the direct influence of factor $\mathrm{i}$ on factor $\mathrm{j} ; \mathrm{i}$ is an integer, with the range as $1 \leq \mathrm{i} \leq \mathrm{n}$ 
Table 1. The variable indexes used for assessing the social impact imposed by large-scale projects in china.

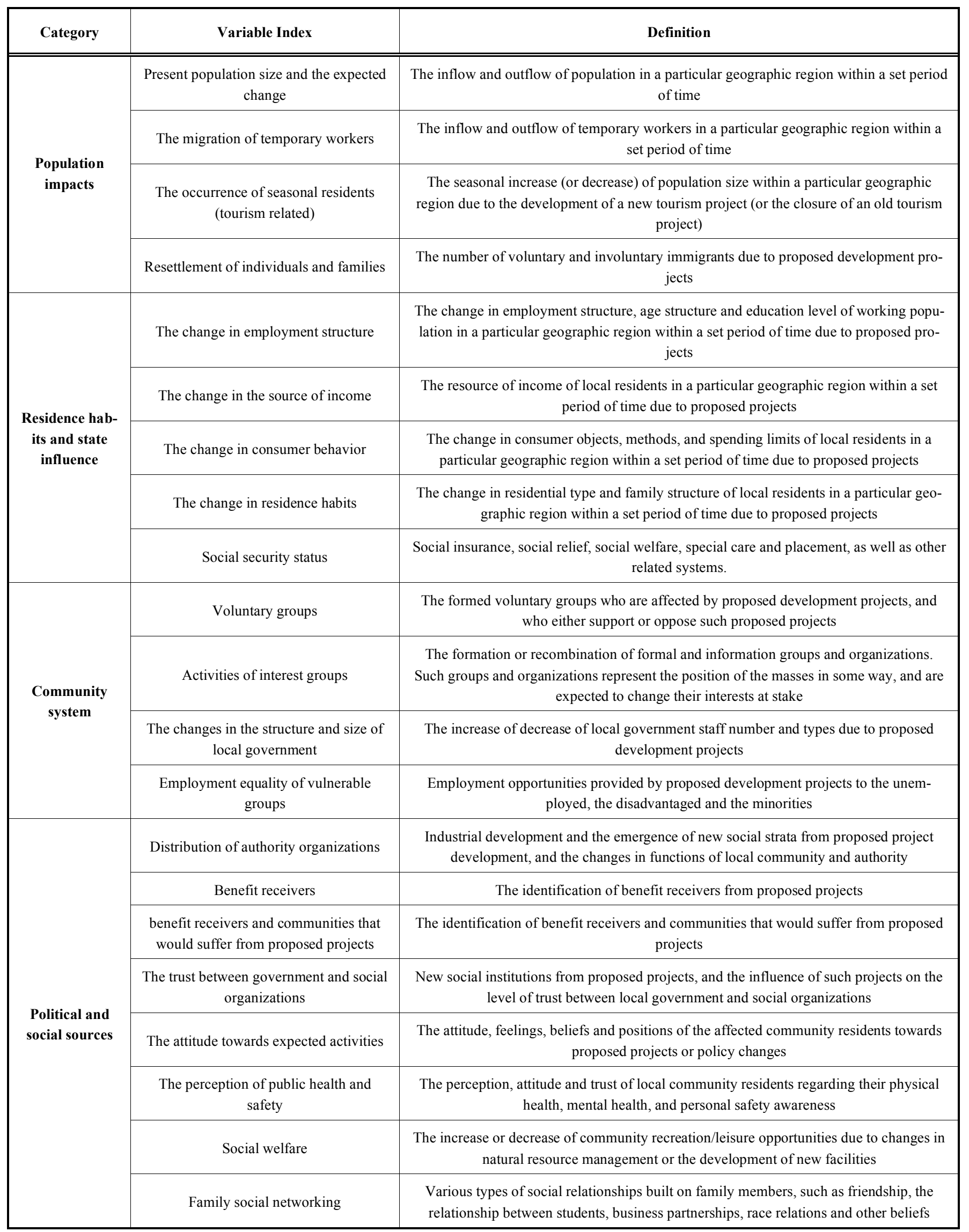


Table 1. Contd......

\begin{tabular}{|c|c|c|}
\hline Category & Variable Index & Definition \\
\hline \hline \multirow{2}{*}{$\begin{array}{c}\text { The } \\
\text { construction of } \\
\text { community } \\
\text { infrastructure }\end{array}$} & Changes in community infrastructure & Changes in community infrastructure due to the alteration of projects and supplies \\
\cline { 2 - 4 } & $\begin{array}{c}\text { The impacts on known cultural, histori- } \\
\text { cal, religious and archaeological sites }\end{array}$ & Anticipated negative impacts on cultural, historical, religious and archaeological sites \\
from proposed construction projects
\end{tabular}

$\mathrm{j}$ is an integer, with the range as $1 \leq \mathrm{j} \leq \mathrm{n}$

when $i=j$, without considering the influence of variables themselves, it is set $\mathrm{v}_{\mathrm{ij}}=0$

The extent of direct impact could be scaled as $0-1,0-5$ or $0-9$ [15].

\subsubsection{The Determination of the Causal Relationships Be- tween Variables and the Relative Importance of Each Variable in the Social Impact Assessment}

The matrix is normalized to establish the combined effect of the matrix. On this basis, the degree each variable affects or be influenced by other variables could be calculated. Meanwhile, the centrality and causality degree of each variable could also be calculated. Consequently, the causal relationships between variables, and the relative importance of each variable in affecting the social impact assessment system could be determined. Detailed steps and calculation formulas are as following [16]:

\section{(1) Normalized direct impact matrix X}

The direct impact matrix $\mathrm{V}$ is standardized in order to analyze the indirect relationships between variables, with the formula shown as:

$$
\begin{aligned}
\mathrm{X} & =\mathrm{V} / \max _{1 \mathrm{sisn}} \sum_{\mathrm{j}=1}^{\mathrm{n}} \mathrm{v}_{\mathrm{ij}} \\
& =\left(\mathrm{X}_{\mathrm{ij}}\right)_{\mathrm{n} \times \mathrm{n}}
\end{aligned}
$$

In this formula: $0 \leq x_{\mathrm{ij}} \leq 1$,

(2) The calculation of comprehensive impact matrix $\mathrm{Z}$ that reflects interdependent relationships between variables

The matrix $\mathrm{Z}$ is obtained by adding up normalized direct impact matrix $X_{1}, X_{2} \ldots X_{n}$, with the formula shown as:

$Z=X_{1}+X_{2}+\ldots+X_{\mathrm{n}}=\left(z_{\mathrm{ij}}\right)_{\mathrm{n} \times \mathrm{n}}$

When $n$ is large enough, approximate calculation of $Z=X(I-X)^{-1}$ could be applied

In this formula: I represents the unit matrix

(3) The calculation of influence degree A and response degree B

The influence degree A is the sum of rows of matrix Z, which shows the comprehensive impact value of the measured variable on other variables. The response degree $\mathrm{B}$ is the sum of columns of matrix $\mathrm{Z}$, which shows the comprehensive response value of the measured variable that is affected by other variables. The formulas are shown as:

$$
A_{i}=\sum_{j=1}^{n} z_{i j}
$$

$B_{j}=\sum_{i=1}^{n} z_{i j}$

where: $1 \leq \mathrm{i} \leq \mathrm{n}, 1 \leq \mathrm{j} \leq \mathrm{n}$

(4) The calculation of centrality degree M and causality degree $\mathrm{U}$

The centrality degree $M$ is the sum of rows and columns of matrix $Z$, which displays the relative importance of the measured variable in the entire social impact assessment system. The causality $U$ is the difference between the sums of rows and columns of matrix $Z$, which displays the causaleffect logics between the measured variable and other variables. If the value is positive, it means that this measured variable imposes a significant influence over other variables, which is named a causal variable. If the value is negative, it means that other variables impose a significant influence over this measured variable, which is named a result variable. The formulas are shown as:

$$
\begin{aligned}
& M=A_{i}+B_{j} \\
& U=A_{i}-B_{i}
\end{aligned}
$$

where: $1 \leq \mathrm{i} \leq \mathrm{n}, 1 \leq \mathrm{j} \leq \mathrm{n}$

The calculation function of EXCEL, such as MMULT and MINVERSE, could be applied to facilitate the calculation process.

\subsubsection{The Make and Analysis of Causal-effect Graph}

According to the influence matrix, when Matrix Laboratory (MATLAB) is applied, the $\mathrm{x}$ and $\mathrm{y}$ axis are named as the centrality degree and the causality degree, respectively, of studied variables, and the exact locations of such variables could be drawn and determined on a two dimensional space. The centrality degree is an index used to assess the importance of assessed variable, whereas the causality degree is used to assess the influence of the assessed variable over other variables. In the causal-effect graph, those variables with right centrality degree are variables with large centrality variation. Since they play important roles in influencing the entire system of social impact assessment, they deserve more attentions from decision makers and managers. When the value of the causality degree is positive, it means that the studied variable would impose a big influence over other variables, and thus is considered as a causal factor. On the other hand, when the value is negative, it means that the studied variable is likely to be affected by other variables, and thus is considered as an effect variable. Clearly, it is essential to figure out the causal factors during the practice of social impact assessment. Therefore, by studying the posi- 
Table 2. The established list of variables for assessing social impacts.

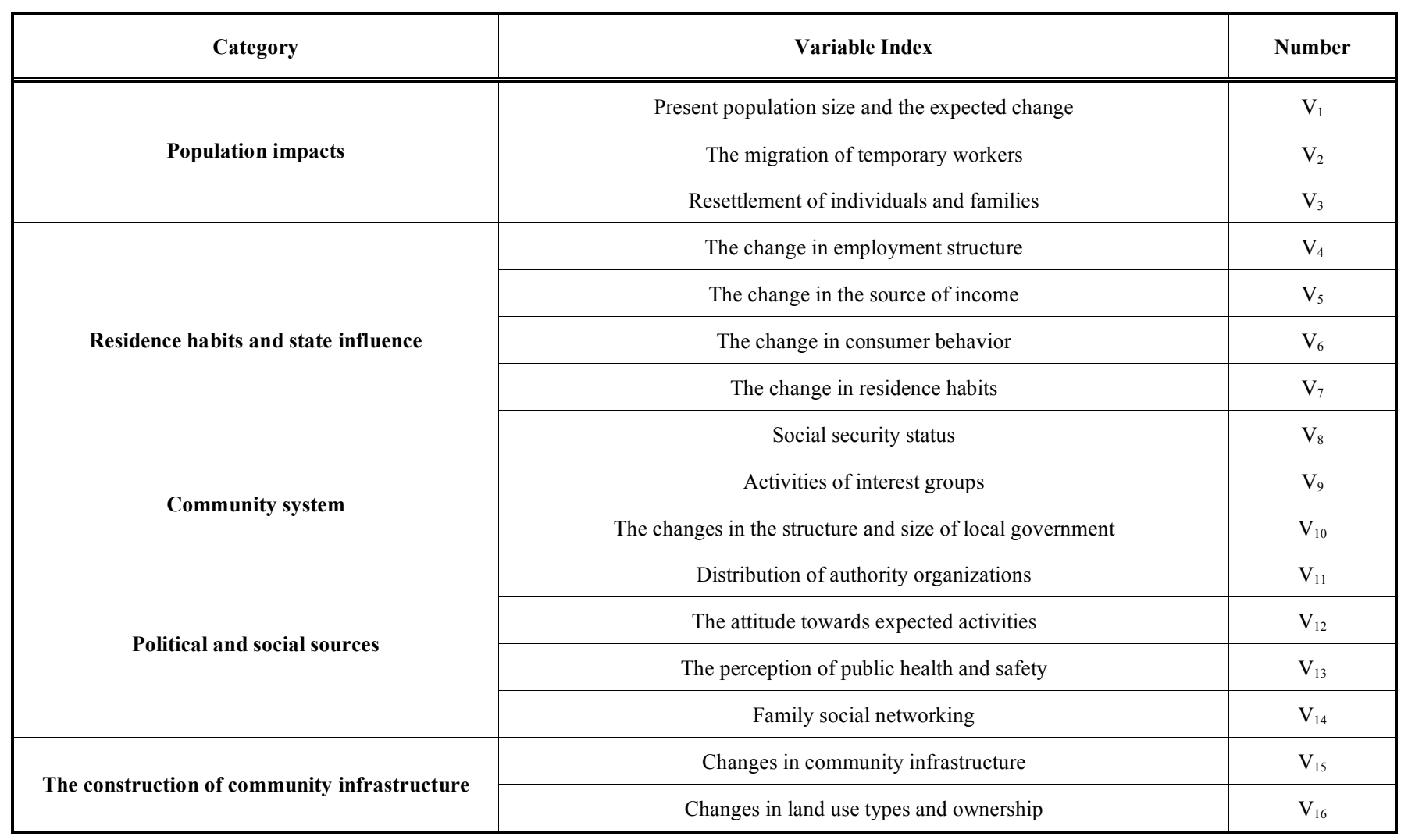

tion and characteristic of each variable in the causal-effect graph, relevant advice could be proposed regarding aspects of social impact assessment, the decision making and management of large-scale engineering projects. In addition, since causal factors impose determining impacts on effect variables, the former can be used for social impact assessment and thus to simplify the assessment system of index variables.

\section{APPLICATION ANALYSIS}

\subsection{Project Overview and the Selection of Variables for Assessing Social Impacts Imposed by the Project}

GangKouwan Reservior Project is located in XiJin River, one of the upstream tributaries of ShuiYangjiang River in Ninguo, Anhui Province. It is a large-scaled water conservancy and hydropower project mainly in flood control, combined with power generation, irrigation, urban water supply, aquaculture and tourism development, and the key project to governance the floods of ShuiYangjiang River watershed. The reservoir river control area of 1120 square kilometers, with a total capacity of 941 million cubic meters, the normal storage level 135 meters, the surface area of 32.8 square kilometers. After the completion of the reservoir, it can improve the flood control standards of Fu Jing and BeijingHangzhou Railway, 318 and 205 National Highway, Xuancheng, Ningguo and other cities and towns, effectively protect about 37,000 square hectares farmland and 45 million people of the watershed, expansion of the irrigated area of about 31,000 square hectares. The reservoir inundation involves about 5 townships (towns), 21 administrative vil- lages, 138 village groups of Ningguo, inundated farmland about 1300 square hectares, reservoir resettlement about 18,096 people. The hydroelectric power station installed capacity of $2 \times 30 \mathrm{MW}$, annual generation capacity of 113 million $\mathrm{kV} \cdot \mathrm{h}$, as a system load, it has a positive effect to improve the power supply quality, improve the water supply guarantee rate of Xuancheng, Ningguo and other cities and towns, it also with tourism and aquaculture development value. The selected reservoir community in the present study also represents the geographic range of social impact assessment. Based on abovementioned lists of variables used for assessing social impacts, the key variables are selected via surveys and interviews of experts and stakeholder. The established list of variables for assessing social impacts imposed by the water diversion project is shown in Table 2 .

\subsection{DEMATEL-based Variable Analysis of Social Im- pact Assessment}

\section{(1) The establishment of direct impact matrix}

30 experts $^{1}$ are selected as survey objects, and the degree of associations between variables is quantified using the 0-5 scale, for which " 0 ", " 1 ", “2”, “3", "4"and "5" represents "no influence", "insignificant weak influence", "weak influence", "strong influence" and "significant strong influence",

\footnotetext{
${ }^{1}$ Composition of expert group:

4 professors majored in related field form universities in the project located area; 6 staffs from social evaluation institutions in the project located area; 6 administrative staffs of the project; 10 professionals from the project located area; 4 staffs from social evaluation institutions outward the project located area.
} 
Table 3. Direct impact matrix.

\begin{tabular}{|c|c|c|c|c|c|c|c|c|c|c|c|c|c|c|c|c|}
\hline $\mathrm{V}_{1}$ & 0 & 3 & 2 & 5 & 3 & 1 & 2 & 0 & 3 & 0 & 2 & 1 & 5 & 3 & 3 & 1 \\
\hline $\mathrm{V}_{3}$ & 3 & 2 & 0 & 3 & 3 & 2 & 2 & 0 & 3 & 0 & 5 & 2 & 2 & 3 & 0 & 0 \\
\hline$V_{6}$ & 0 & 0 & 0 & 0 & 0 & 0 & 2 & 0 & 0 & 0 & 2 & 5 & 3 & 2 & 0 & 0 \\
\hline$V_{7}$ & 0 & 0 & 0 & 5 & 0 & 3 & 0 & 0 & 0 & 0 & 0 & 3 & 0 & 2 & 0 & 0 \\
\hline $\mathrm{V}_{8}$ & 3 & 2 & 2 & 0 & 0 & 2 & 0 & 0 & 3 & 0 & 0 & 2 & 3 & 0 & 0 & 0 \\
\hline$V_{12}$ & 5 & 3 & 5 & 3 & 0 & 3 & 2 & 0 & 3 & 0 & 0 & 0 & 3 & 0 & 0 & 0 \\
\hline$V_{13}$ & 3 & 1 & 3 & 2 & 0 & 0 & 0 & 0 & 5 & 0 & 0 & 3 & 0 & 3 & 2 & 1 \\
\hline $\mathrm{V}_{14}$ & 1 & 2 & 2 & 2 & 0 & 0 & 3 & 0 & 0 & 0 & 0 & 0 & 0 & 0 & 0 & 0 \\
\hline$V_{15}$ & 0 & 0 & 0 & 0 & 0 & 0 & 3 & 0 & 0 & 0 & 0 & 2 & 3 & 0 & 0 & 1 \\
\hline$V_{16}$ & 0 & 0 & 0 & 0 & 0 & 0 & 2 & 0 & 3 & 0 & 0 & 2 & 3 & 0 & 1 & 0 \\
\hline
\end{tabular}

respectively. The survey results are analyzed and averaged to reflect the extent of direct influence and to establish the direct impact matrix as shown in Table $\mathbf{3}$.

(2) The calculation of normalized direct impact matrix $X$ and comprehensive influence matrix $\mathrm{Z}$ here.

Due to page limits, the calculations details are not shown

(3) The calculation of influence degree A, response degree $B$, centrality degree $M$ and causality degree $U$

The calculation details are shown in Table 4.

\subsection{The Causal-Effect Graph and Relevant Analysis}

According to the combined effects of a relational table, Matrix Laboratory (MATLAB) is applied to mark each risk factor in the coordinates as shown in Fig. (1).

The following conclusions could be drawn:

The first five parameters of the centrality degree: $\mathrm{v}_{12}, \mathrm{v}_{3}$, $\mathrm{v}_{1}, \mathrm{v}_{9}, \mathrm{v}_{13}$

The first five parameters of the causality degree: $v_{1}, v_{8}$, $\mathrm{v}_{2}, \mathrm{v}_{3}, \mathrm{v}_{16}$

Parameters with negative causality degree: $\mathrm{v}_{14}, \mathrm{v}_{7}, \mathrm{v}_{9}, \mathrm{v}_{4}$, $\mathrm{v}_{6}, \mathrm{v}_{5}, \mathrm{v}_{12}$

The centrality degree is an important index for assessing the relative importance of a measured variable. It can be seen from the above graph that the first five parameters of the centrality degree include $\mathrm{v}_{12}$ (the attitude toward the expected activities), $v_{3}$ (the resettlement of individuals and families), $v_{1}$ (current population size and expected changes), $\mathrm{v} 9$ (activities of benefit receivers) and $\mathrm{v}_{13}$ (the perception of public health and safety), with corresponding value of the centrality degree as $4.203,3.467,3.462,3.390,3.293$, respectively. Therefore, these five variables play important roles in affecting the practice of social impact assessment. The causality degree is used to evaluate the influence of a measured variable on other variables. When the value is positive, it means that this measured variable imposes a significant influence over other variables, which is named a

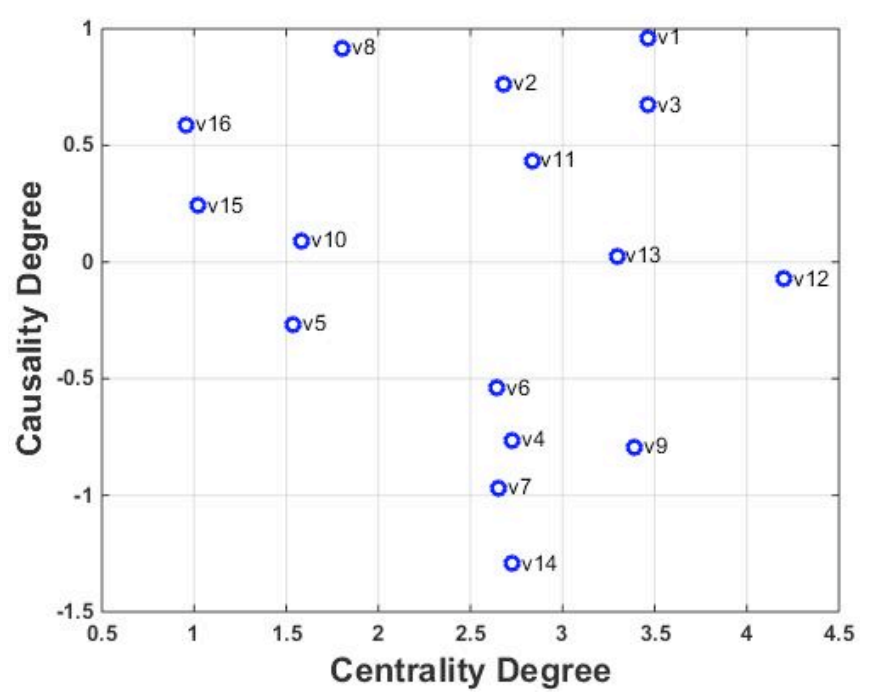

Fig. (1). The causal-effect graph for assessing social impacts imposed by the project. 
Table 4. Comprehensive influence table.

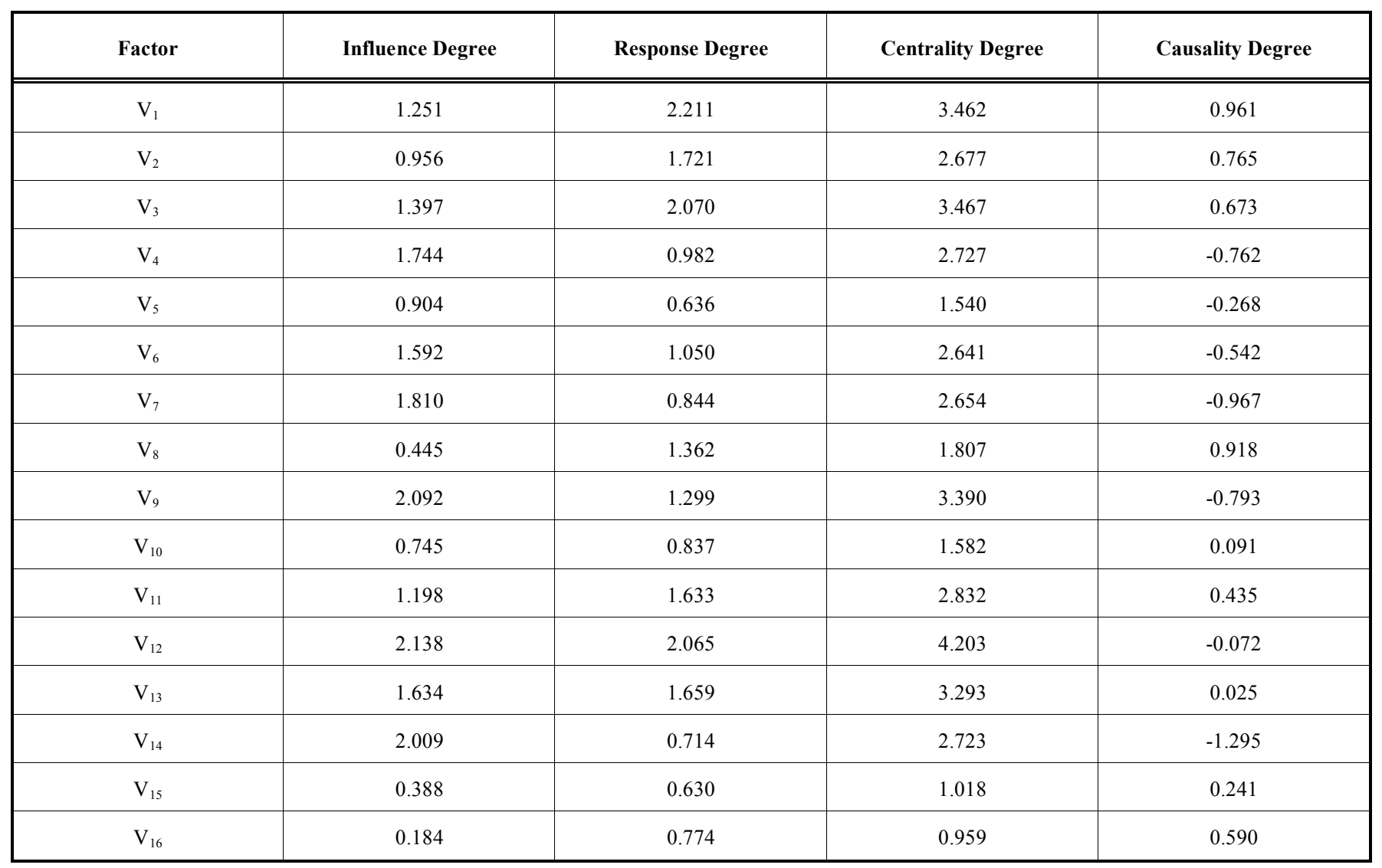

causal variable. By contrast, when the value is negative, it means that other variables impose a significant influence over this measured variable, which is named a result variable. The first five parameters of the causality degree include $\mathrm{v}_{1}$ (current population size and expected changes), $\mathrm{v}_{8}$ (social security status), $v_{2}$ (the flow of temporary workers), $v_{3}$ (the resettlement of individuals and families) and $\mathrm{v}_{16}$ (land use types and ownership changes), with corresponding value of the causality degree as $0.961,0.918,0.765,0.673,0.590$, respectively. Therefore, these five variables are likely to impose impacts on other variables. Variables with negative causality degree include $\mathrm{v}_{14}$ (social networking of families), $\mathrm{v}_{7}$ (the change of living habits), $\mathrm{v}_{9}$ (activities of benefit receivers), $v_{4}$ (the change of employment structure), $v_{6}$ (the change of consumer behavior), $\mathrm{v}_{5}$ (the change of income source) and $v_{12}$ (the attitude toward the expected activities), with corresponding value as $-1.295,-0.967,-0.793,-0.762$, $0.542,-0.268,-0.072$, respectively. Therefore, these variables are likely to be affected by other variables. Therefore, the key point managers and decision makers should pay more attention includes the attitude of local residents towards local construction, the resettlement of individuals and families by government effort, demographic changes due to the construction of proposed projects, activities of benefit receivers, the perception of public heath and safety. The major variables that should be collected for assessing social impacts include current population size and expected changes, social security status, the flow of temporary workers, the resettlement of individuals and families, and changes in land use types and ownership.

\section{CONCLUSION}

The practice of social impact assessment of large-scale projects that might affect human survival and development has inspired a great deal of public attention and international consensus. However, issues such as the ambiguity of available indexes for social impact assessment and the lack of interoperability have led the public to focus on studies of measurable impact or variables that are convenient to survey in the political field, including demographic changes, job opportunities and usage services. Mathematical analysis methods have shown evidence that when inherent interdependent relationships exist among variables, it is possible to describe the basic structure manifested by all involving variables by selecting the minimum number of variables. As a result, large dataset could be downgraded to a simpler level, the essence of the problem could be easily grasped, and the complex index system could be simplified. Meanwhile, a solid basis could be established for further statistical analysis [17]. Therefore, the present study establishes the variable system for assessing social impacts imposed by large-scale projects that suits China's specific situations well. Furthermore, by implementing DEMATEL method, the interdependent relationships among variables could be determined, and the social impact assessment of large-scale projects could be quantified. As a result, those key variables that would affect social impact assessment of large-scale projects are successfully identified, and the present study thus provides an effective approach of variable selection for assessing the social impact of launched large-scale projects in China. 


\section{CONFLICT OF INTEREST}

The authors confirm that this article content has no conflict of interest.

\section{ACKNOWLEDGEMENTS}

This work was supported by the National Social Science funded project from China: Proactive assessment of social impacts imposed by large-scale projects. (Grant No. 12BJY021).

\section{REFERENCES}

[1] X. Y. Lu, P. L. Li, and G. J. Chen, China's Social Situation Analysis and Prediction in 2012, Social Sciences Academic Press: Beijing, China, 2012.

[2] R. Slootweg, F. Vanclay, and M. V. Schoolten, "Function evaluation as a framework for the integration of social and environmental Impact assessment", Impact. Assess. Proj. Apprais., vol. 19, pp. 1928, 2001.

[3] S. Jacob, L. Ouvrard, and J. F. Bélanger, "Participatory evaluation and process use within a social aid organization for at-risk families and youth", Eval. Prog. Plann., vol. 34, pp. 113-123, 2011.

[4] J. Schirmer, "Scaling up: assessing social impacts at the marcoscale", Environ. Imp. Assess. Rev, vol. 31, pp. 382-391, 2011.

[5] R. J. Burdge, "The practice of social impact assessment background", Impact Assess. Proj. Apprais., vol. 21, pp. 84-88, 2003.

[6] Interorganizational Committee on Guidelines and Principles for Social Impact Assessment, "Guidelines and principles for social impact assessment”, Impact Assess., vol. 12, pp. 107-152, 1994.
[7] R. J. Burdge, "Social impact assessment: state of the art", Impact Assess., vol. 14, pp.57-59, 1995.

[8] Asian Development Bank, Handbook for Incorporation of Social Dimensions in Project, 1994.

[9] C. N. Taylor, C. H. Bryan, C. G. Goodrich, and D. S. Ge, Social Assessment: Theory, Process and Techniques. Chongqing University Press: Chongqing, China, 2009.

[10] M. L. Tseng, "A causal and effect decision making model of service quality expectation using grey--fuzzy DEMATEL approach", Expert Syst. Appl., vol. 36, pp. 7738-7748, 2009.

[11] Y. J. Chiu, H.C. Chen, G. H. Tzeng, and J. Z. Shyu, "Marketing strategy based on customer behavior for the LCD-TV", Int. J. Manag. Dec. Making, vol. 7, pp. 143-165, 2006.

[12] S. Hori, and Y. Shimizu, "Designing methods of human interface for supervisory control systems", Control Eng. Pract., vol. 7, pp. 1413-1419, 1999.

[13] A. Stolp, W. Groen, J. V. Vliet, and F. Vanclay, "Citizen values assessment: incorporating citizens' value judgements in environmental impact assessment", Impact Assess. Proj. Apprais., vol. 20, pp. 11-23, 2002.

[14] C. W. Li, and G. H. Tzeng, "Identification of a threshold value for the DEMATEL method using the maximum mean de entropy algorithm to find critical services provided by a semiconductor intellectual property mall", Expert Syst. Appl., vol. 36, pp. 9891-9898, 2009.

[15] K. C. Zhang, J. F. Chen, and J. L. Zhang, Introduction to Systems Engineering, Science Press: Beijing, China, 2010.

[16] W. W. Wu, "Choosing knowledge management strategies by using a combined ANP and DEMATEL approach", Expert Syst. Appl., vol. 35, pp. 828-835, 2008.

[17] F. Vanclay, "Conceptualising social impacts", Environ. Imp. Assess. Rev., vol. 22, pp. 183-211, 2002.

Received: October 10, 2014
(c) Shen et al.; Licensee Bentham Open.

Revised: December 07, 2014

Accepted: January 21, 2015

This is an open access article licensed under the terms of the Creative Commons Attribution Non-Commercial License (http://creativecommons.org/licenses/by-nc/3.0/) which permits unrestricted, non-commercial use, distribution and reproduction in any medium, provided the work is properly cited. 